\title{
Avaliação de processo do programa mais gestão na perspectiva dos atores envolvidos na implementação
}

\section{Process assessment of the mais gestão program from the perspective of the actors involved in the implementation}

\author{
Rafael Guimarães Farias', Alair Ferreira de Freitas" \\ ${ }^{\text {I }}$ Universidade do Estado da Bahia, Salvador, BA. rafafeabcruz@gmail.com \\ ${ }^{\text {II }}$ Universidade Federal de Viçosa, Viçosa, MG. alairufv@yahoo.com.br
}

\section{RESUMO}

O presente artigo analisa o Programa Mais Gestão - PMG, uma política pública do governo federal voltada à qualificação na gestão das cooperativas da agricultura familiar. É uma pesquisa predominantemente qualitativa com características exploratória e, através de entrevistas guiadas por um roteiro de questões semiestruturadas. As entrevistas foram analisadas a partir de três dimensões: de implementação, organizativa e territorial. Evidencia-se nos achados da pesquisa que há atrasos burocráticos no PMG que dificultam, por parte da entidade de ATER, a implementação dos instrumentos das chamadas públicas - pré-diagnóstico, diagnóstico, plano de ação e aprimoramento. Os resultados da dimensão organizativa são distintos entre as cooperativas e, as mais estruturadas tem aproveitado melhor o PMG. Estes resultados são reiterados na análise da dimensão territorial onde tais elementos traduzem o dinamismo do cooperativismo em determinados municípios e podem explicar a proatividade das organizações em resposta aos estímulos do PMG.

Palavras-chave: cooperativas; política pública; desenvolvimento rural.

\section{ABSTRACT}

The present research is predominantly qualitative with exploratory characteristics and, through interviews guided by a script of semistructured questions. The interviews were analyzed from three dimensions: implementation, organizational and territorial. It is evident in the research findings that 
there are bureaucratic delays in the MMP that make it difficult for the rural extension system entity to implement the public call instruments - pre-diagnosis, diagnosis, action plan and improvement. The results of the organizational dimension are distinct among cooperatives, and the more structured have made better use of MMP. These results are reiterated in the analysis of the territorial dimension where these elements reflect the dynamism of cooperativism in certain municipalities and can explain the proactivity of the organizations in response to the MMP stimuli.

Keywords: cooperatives; public policy; rural development.

\section{INTRODUÇÃO}

Os dados do Censo agropecuário realizado pelo IBGE (2006) apontam que a agricultura familiar brasileira possui 4.367 .902 estabelecimentos, isso representa $84,4 \%$ do total de estabelecimentos agropecuários. No entanto, ocupam apenas $24,3 \%$ da área destinada à agricultura. Ainda assim, foram responsáveis por $87 \%$ da produção nacional de mandioca, $70 \%$ da produção de feijão, 46\% do milho, 38\% do café, $34 \%$ do arroz, $58 \%$ do leite, $59 \%$ do plantel de suínos, 50\% das aves, 30\% dos bovinos e, ainda, $21 \%$ do trigo. Demonstrando a potencialidade para a produção de alimentos. Porém, enfrentam desafios na organização, industrialização e comercialização desta produção.

O Ministério do Desenvolvimento Agrário - MDA formula políticas públicas para a agricultura familiar, majoritariamente voltada para a agregação de valor e geração de renda. Neste sentido, tem incentivado a agricultura familiar para a organização de sua base produtiva e melhoria da gestão de suas organizações econômicas, visando à inserção qualificada nos mercados institucionais (Programa de Aquisição de Alimentos - PAA e Programa Nacional de Alimentação Escolar - PNAE), e privados. O PNAE adiquire uma relação direta com a agricultura familiar a partir da Lei $n^{\circ} 11.947$, de 16 de junho de 2009 que estabelece a compra mínima de 30\% da alimentação escolar oriundas da agricultura familiar. Junto ao PNAE, o PAA está comprometido com a segurança alimentar e nutricional da população, não obstante com o desenvolvimento da agricultura familiar proporcionando a abertura de canais de mercados institucionais para a comercialização da produção local. 
Assim, a agricultura familiar passa a acessar esses novos mercados institucionais e, na medida em que esses atores constroem sua trajetória de participação no programa, apresentam dificuldades, necessitando do provimento de assistência técnica. O MDA passa a contratar as organizações, por meio de chamadas públicas, para prover Assistência Técnica e Extensão Rural - ATER gratuita com público preferencial nos empreendimentos da agricultura familiar, participativa, de base ecológica, com equidade nas relações de gênero, geração, raça e etnia, contribuindo para o desenvolvimento sustentável e para a segurança e soberania alimentar e nutricional.

Com foco diferente das políticas de ATER anteriores, em 2009 o MDA implementa um projeto piloto conhecido como nutre, uma experiência de ATER para pessoa jurídica, implementado em 13 estados, totalizando R\$ 10 milhões investidos, beneficiando às cooperativas da agricultura familiar para que estas se adequem às demandas do PNAE nos maiores municípios, justamente por propiciar melhorias na gestão e no acesso aos mercados. O nutre era orientado para o mercado institucional, visando apresentar os dados de produção das cooperativas e subsidiar as prefeituras para atender as exigências da compra da merenda escolar oriundas da agricultura familiar - essa se constitui a ação embrião à criação do Programa Mais Gestão - PMG.

Nesse ensejo, a partir de 2012 o governo investe em um programa específico de assistência técnica para qualificação e fortalecimento da gestão das cooperativas. O Programa Mais Gestão - PMG surge como uma metodologia de ATER centrada no tripé gestão - produto - mercado, guiado por um conjunto de instrumentos normativos que delineiam como as ações devem ser operacionalizadas. No âmbito da implementação do PMG relacionam-se o MDA, a entidade prestadora do serviço de ATER e as cooperativas beneficiárias pelo programa. O PMG pretende "fortalecer os empreendimentos da agricultura familiar por meio do aprimoramento da gestão visando à inserção nos mercados institucionais e privados". O maior objetivo do programa é o de qualificar essas cooperativas para garantir seu acesso a mercados e 
as oportunidades abertas pelo Programa Nacional de Alimentação Escolar - PNAE e o Programa de Aquisição de Alimentos - PAA.

Desde a primeira chamada pública até a última, verifica-se a significativa necessidade do MDA no sentido de aperfeiçoamento das chamadas para melhor atender as especificidades das cinco macros regiões do Brasil. Para contribuir com informações que possam melhorar o conhecimento sobre o PMG e trazer um ponto de vista dos beneficiários do programa, este trabalho objetivou realizar uma avaliação do processo de implementação do PMG na perspectiva dos atores envolvidos no processo de implementação do PMG, não somente na governança da gestão pública dos recursos do programa, entendendo governança como os mecanismos, as estruturas e as diretrizes que foram estabelecidas pelo MDA para implementação do PMG.

O artigo está estruturado em cinco seções, sendo a primeira esta introdução. Já na segunda seção discute o referencial teórico sobre políticas públicas e a ATER com foco em cooperativas da agricultura familiar. A seção três delimita os procedimentos metodológicos, seguindo com a seção quatro com os resultados na perspectiva dos benecifiários sobre o PMG. Por fim, as considerações finais da pesquisa.

\section{REFERENCIAL TEÓRICO}

\subsection{Avaliação de políticas públicas na perspectiva dos beneficiários}

Alguns elementos são úteis para compreender o conceito de política pública, para Grisa e Scheider, (2014), alguns elementos são úteis para compreender uma Política Pública. Primeiro, a política cria um quadro normativo de ação que pode estar explícito, ou não, mas estará sempre presente e os trabalhos científicos de análise de política devem levar em conta este aspecto buscando identificar e reconstruir a concepção e os objetivos das mesmas com vistas a revelar esse quadro normativo. 
Essa etapa de modelização da política avaliada é de fundamental importância e garante uma "fotografia nítida" do conjunto de programas e ações públicas que envolvem a política. Segundo, tem relação com a composição da força pública e competência, a ação do Estado é autoritária e coercitiva, porém, as vezes não são explícitas, sendo sempre resultado de uma dada interação entre os espaços públicos e privados. Por fim, a perspectiva de que na operacionalização de políticas públicas costuma-se estabelecer uma ordem no contexto local que reforça a magnitude da compreensão do conjunto dos atores envolvidos pela ação do Estado.

As políticas públicas são compreendidas por Hofling (2001), como de responsabilidade do Estado, quanto à implementação e manutenção a partir de um processo de tomada de decisões que envolvem órgãos públicos e diferentes organismos e agentes da sociedade relacionados à política implementada. Rua (1997) cita que, as políticas públicas são um conjunto organizado de atuações proposta pelo Estado, com propósito de resolver os conflitos da sociedade de maneira pacífica. Os indivíduos que estão envolvidos nestes conflitos são denominados atores políticos, que podem ser públicos, privados ou do terceiro setor. O ator, em determinada situação, pode ser definido como um único indivíduo ou como um grupo funcionando como um ator corporativo (OSTROM, 2007).

Sendo o Estado o provedor das políticas públicas, e necessitando gerir os recursos que são escassos, torna-se indispensável os mecanismos de monitoramento e avaliação das políticas públicas, afim de melhor e aproveitar os recursos. Esta é uma empreitada multidisciplinar que visa interpretar as causas e consequências da ação do governo (WILDAVSKY, 1979, p. 17).

A avaliação para Ortegon et al. (2005), é uma reflexão sistemática da concepção, eficiência, eficácia, resultados de um projeto em andamento ou concluídos. Diferente de monitoramento que é uma avaliação continuada da implementação do projeto (WORLD BANK, 1996). Na prática, essa avaliação das políticas públicas pode acontecer 
no início, durante ou após a implementação do programa. Referente ao momento pode ser antes ou ex- ante, de processo, após ou ex-post.

A avaliação de processo é realizada durante a fase de implementação, é também denominada gestão contínua, monitoração ou avaliação concomitante. Seu objetivo é monitorar o andamento das ações, melhorar o desempenho e, com isso, promover mudanças, se necessárias, nos rumos das intervenções (COHEN e FRANCO, 2008).

Para melhoria das políticas públicas, a realização da avaliação de processo é muito importante com vista na garantia de bons resultados, ou seja, a avaliação da política pública que ainda está vigente, adequando assim, cada erro encontrado. Para Chiavenato (2010), no controle administrativo da política pública, deve-se controlar todo processo, funções e objetivos planejados. Ou seja, controlar o andamento de cada ação e proceder com as possíveis correções desejáveis para alcançar o resultado planejado em tempo hábil.

Na implementação de um projeto, desenvolver os serviços de acordo com o planejamento inicial é o que se espera alcançar. As principais ocorrências nessa fase são: ativar a comunicação entre os membros da equipe do projeto; executar as etapas previstas e programadas; utilizar os recursos humanos e materiais, sempre que possível, dentro do que foi programado (quantidades e período de utilização); efetuar reprogramação no projeto segundo seu status quo e adotando os planos e programas iniciais como diretrizes, eventualmente, mutáveis (MENEZES, 2003, p. 67).

Garantir algum tipo de controle da política pública considerando as perspectivas apresentadas pelos beneficiários fortalece a participação social, contribuindo para a governança da política pública. Na esfera pública, melhorar a eficiência das ações governamentais é um dos desafios enfrentados pelos governos em todo o mundo. A boa gestão pública também está ancorada em boas práticas de 
governança corporativa. Os mecanismos de governança se estabelecem pela implementação de políticas e iniciativas que visam promover a transparência e a prestação de contas na administração pública, criando assim ambiente de confiança nos diversos setores da sociedade.

Conforme Mimicopoulos; Kyj e Sormani (2007), governança na área pública refere-se aos acordos formais e informais que determinam como as decisões são tomadas e como as ações públicas são realizadas a partir da perspectiva de manter valores constitucionais de um país. De acordo com Matias-Pereira (2005), a governança na esfera pública busca o equilíbrio entre todos os envolvidos, para que o bem comum prevaleça sobre os interesses das pessoas e grupos.

O Programa Mais Gestão é uma política pública voltada para o fortalecimento da gestão em cooperativas da agricultura familiar (beneficiários do programa). O PMG foi formulado pelo MDA e a sua execução se dá através de organizações prestadoras do serviço de Assistência Técnica e Extensão rural - ATER.

\subsection{ATER focada na gestão de cooperativas}

A trajetória histórica da ATER no Brasil, como política pública de desenvolvimento rural, pode ser agrupada em três fases da ascensão à crise, no período entre 1948 - 1989. Os três momentos da Extensão Rural (ER) no Brasil são: 1 Humanismo assistencialista, 2- Difusionismo produtivista, 3- Humanismo crítico.

Na década de 1940 o humanismo assistencialista prevaleceu na extensão rural enquanto o Estado brasileiro dava reduzida importância ao desenvolvimento econômico no campo brasileiro. Minas Gerais e São Paulo são precursores da ER no país, esses estados eram mais desenvolvidos e foram intencionalmente escolhidos para iniciar a ER brasileira. 
De acordo com Silva (2009), esses pioneiros da ER nacional foram impulsionados por interesses internacionais e financiados pela American International Association (AIA). Inspirado no modelo Farm Security Admnistration, Minas Gerais alavancou a experiência embrionária através de uma associação sem fins lucrativos, a Associação Rural de Créditos e Assistência Rural (ACAR). Ainda como parte desse processo, em 1948 e 1949, a Sociedade Rural Brasileira (SRB) e o Instituto de Economia Rural (IER) realizaram debates relativos à produção de algodão, café e a manutenção de um solo agricultável.

A concepção da ER voltada para a família se esgota em 1962, passando para um novo momento nos planos de governo, elegendo a partir de então, os grandes e médios produtores como público alvo das políticas. Na medida em que o Brasil ia seguindo este caminho os novos objetivos nacionais iam tomando o espaço do humanismo assistencialista antes presente na ER.

Os novos objetivos nacionais visavam a modernização no meio rural, logo a antiga equipe composta por um agrônomo e uma economista doméstica preocupados com a família dá lugar para a contratação de agrônomos e veterinários comprometidos com a produtividade. Assim, os serviços de ATER ficaram conhecidos como difusionismo produtivo com característica "de cima para baixo", persuasiva e insensível ao conhecimento dos agricultores (BRASIL, 2010).

Havia uma clara seletividade das políticas públicas em prol dos grandes e médios produtores que passaram a deter, cada vez mais, o monopólio da terra e modernizar-se tecnologicamente (RODRIGUES, 1997). Com essa concepção seletiva, a ATER é conduzida até meados da década de 80 quando, após a conclusão da modernização no meio rural no Brasil, esse modelo de ATER é duramente questionado, tanto pela seletividade do público atendido e baixa abrangência no serviço, quanto pela concepção teórica de desenvolvimento agrícola insustentável. 
Impulsionado pelo esgotamento do difusionismo, inaugura-se o período conhecido como humanismo crítico principalmente baseado na crítica Freireana ao que ele denominava invasão cultural. A partir desse momento histórico as ideais Freiriana passaram a ser valorizadas e a ER passou a ser vista como um processo educativo com um olhar holístico e não retido somente às técnicas mais avançadas. $\mathrm{O}$ extensionista deve estimular a participação dos beneficiários, estabelecendo uma comunicação horizontal com os agricultores (RODRIGUES, 1997).

Em 1990, houve a liquidação da empresa de ATER no Brasil e o desmonte de todo sistema, ficando a ER a cargo dos estados federativos. No entanto, em menos de uma década o governo federal retoma os investimentos na ATER coordenados pelo recém-criado, em 1999, Ministério do Desenvolvimento Agrário - MDA que surge no cenário político com a intenção de promover um desenvolvimento integrado no meio rural.

A partir de 2003, se materializa um novo modelo de ATER para o país. A ATER no Brasil sempre esteve ligada às políticas de crédito agrícola e, não por acaso o principal programa implementado pelo MDA, em termos de abrangência e disponibilidade de recursos, é o PRONAF. Em meio a subordinação da ATER às políticas de crédito agrícola, durante mais de 80 anos de institucionalização da extensão rural no Brasil, as ações sempre estiveram empenhadas na melhoria da produção e produtividade agrícola. Deste modo, o MDA renova o seu antigo foco unilateral da ATER voltada para o aumento da produtividade agropecuária e inaugura no Brasil uma ATER específica para a gestão dos empreendimentos da agricultura familiar, objetivando melhores resultados na implementação do PAA e PNAE.

Esse processo de atrelamento das políticas de ATER trouxeram perturbações acerca do sentido da extensão rural, do verdadeiro motivo da ATER. Logo, as reações da sociedade civil e das organizações e movimentos sociais pressionaram o governo em busca de alternativas. Nesse contexto, a orientação das políticas de ATER 
passaram a contribuir com o que se chama de "o novo rural", despertando para os limites existentes na dicotomia entre rural e urbano, passando a considerar a multifuncionalidade da agricultura familiar e a importância da renda "não agrícola" das atividades econômicas do meio rural (GRISA e SCHNEIDER, 2014).

Com a imediata dificuldade apresentada pelos agricultores no acesso dessas políticas, percebe-se novas demandas apresentadas de forma primordial para a realização de ações capazes de melhorar o acesso dos agricultores familiares aos mercados institucional e privado. Deste modo, o MDA renova o seu antigo foco unilateral da ATER voltada para a produção e inaugura no Brasil uma assistência técnica específica para a gestão dos empreendimentos da agricultura familiar, objetivando melhores resultados na implementação do PAA e PNAE.

Por conseguinte, o serviço de ATER deixa de ter a concepção voltada apenas para as questões relacionadas ao aumento da produtividade agrícola e passa a focalizar também na melhoria na gestão das organizações para a inclusão dos agricultores nos mercados institucionais, pois, esses agricultores possuem diretores com pouca ou nenhuma "intimidade" com questões relacionadas a balanço financeiro, mercados e comercialização da produção.

Perseguindo esse novo horizonte estratégico, o MDA criou um programa de ATER específico para as organizações aprimorarem o tripé gestão - produto mercado. Também conhecido como “ATER Mais Gestão", em 2012, o “Programa Mais Gestão" surge com o objetivo principal de fornecer um serviço de ATER capaz de qualificar a gestão das cooperativas da agricultura familiar e garantir o acesso ao mercado institucional do PAA e PNAE. Através de chamadas públicas, o MDA promove a contratação de entidades de ATER com know how para execução do serviço. 
2.2.1 O programa mais gestão como estratégia de ação

O Programa Mais Gestão (PMG) nasceu em 2012 como uma metodologia de ATER centrada no tripé gestão - produto - mercado, guiado por um conjunto de instrumentos normativos que delineiam como as ações devem ser operacionalizadas. Espera-se com o PMG, fortalecer os empreendimentos da agricultura familiar por meio do aprimoramento da gestão visando a inserção nos mercados institucionais (PAA, PNAE) e privados (MDA, 2013).

O instrumento utilizado para o financiamento dessa ATER são as chamadas públicas, onde o MDA repassava o recurso financeiro para as entidades executoras realizarem as ações preestabelecidas. O público beneficiário nas chamadas públicas do PMG são os empreendimentos coletivos da agricultura familiar, aqui entendidos como arranjos coletivos de agricultores familiares no qual incluem-se as cooperativas, caracterizados como pessoa jurídica e detentores da DAP Jurídica (Declaração de Aptidão do Pronaf).

Na implementação do PMG, a entidade contemplada com a chamada pública, deve executar cada atividade preestabelecida nos instrumentos normativos: (i) PréDiagnóstico, (ii) Diagnóstico, (iii) Plano de Ação e, (iv) Plano de Aprimoramento. O denominado Pré-Diagnóstico é a etapa de levantamento das informações sobre a realidade das cooperativas através da aplicação, pelas entidades de ATER contratadas, do formulário de caracterização. O objetivo desse instrumento é o levantamento de dados preliminares para definição do perfil da cooperativa, antecedendo a aplicação do diagnóstico. Esses dados contemplam informações acerca do histórico e caracterização social, produtiva e comercial das organizações atendidas. Para realizar - Diagnóstico, os técnicos de ATER visitam as cooperativas para compreender aspectos estruturais, rotina de atividades da cooperativa, levantamento de informações financeiras e de acesso aos mercados. 
A partir do levantamento dos diagnósticos, observa-se as áreas de significativa importância para as cooperativas para a construção de um plano de aprimoramento participativo, implementação e acompanhamento de resultados através de um plano de ação que deve visar, sobretudo, o aprimoramento das diferentes áreas funcionais das cooperativas: organizacional, comercial, industrial, ambiental, financeira e pessoal.

Através desse conjunto de atividades designadas pelo Estado que as entidades de ATER se balizam durante todo o processo de implementação das atividades do PMG, relacionam-se para isto: os órgão públicos, a entidade executora de ATER, as cooperativas e as entidades territoriais parceiras das cooperativas, conformando uma rede que será objeto da pesquisa.

É importante ressaltar, que foi realizado um estudo exploratório por um grupo de pesquisadores convidados pelo MDA e apontaram elementos importantes sobre a execução do PMG, desde a influência da implementação do Programa, gerando externalidades específicas para as cooperativas beneficiárias, como a rede de atores por meio da qual se desenvolvem suas atividades. Segundo esse estudo mencionado, a interação entre esses atores podem produzir efeitos distintos que influenciam nos resultados da Política Pública.

Além da execução contratual a que se destinava a implementação do PMG, o MDA pensou o Programa para funcionar como um articulador de outras políticas públicas do MDA (crédito rural, agroindustrialização, mercado institucional, dentre outras) no interior das cooperativas. É também por esse motivo, que a entidade contratada se empenha em mediar a aproximação entre as cooperativas atendidas e com as entidades territoriais parceiras, a fim de inserir as beneficiárias em redes de parcerias institucionais/políticas que fortaleçam as políticas públicas da agricultura familiar. 


\section{PROCEDIMENTO METODOLÓGICO}

A presente pesquisa é predominantemente qualitativa com características exploratória e, através de entrevistas guiadas por um roteiro de questões semiestruturadas. Para tanto foram escolhidos casos distintos em termos de características das cooperativas, dos contextos territoriais em que se localizam e do desempenho em relação aos estímulos realizados pelas entidades de ATER contratadas no âmbito do PMG. Portanto, trata-se da definição de uma amostra simples e intencional, que depende do julgamento do pesquisador a partir de suas intenções com a pesquisa (COCHRAN, 1965).

A proposta desta pesquisa consistiu em investigar com profundidade casos de sucesso e de insucesso no desempenho das organizações cooperativas a partir das intervenções do Programa Mais Gestão - PMG no ano de 2016. Ou seja, procurou-se definir cooperativas que apresentassem situações distintas entre si, mas não especificamente de suas condições operacionais ou porte, mas sim de sua evolução diante das ações das entidades de ATER, buscando verificar como elas impactaram nas cooperativas e que condições destas organizações e seus territórios favoreceram ou não tal evolução.

O objeto deste estudo são as cooperativas beneficiárias pelo Programa Mais Gestão - PMG na Região Sudeste do Brasil, especificamente os estados do Espirito Santo, Minas Gerais e São Paulo, onde foram contratadas quatro diferentes entidades de Assistência Técnica e Extensão Rural - ATER, as quais possuem diferentes estruturas, métodos e pessoal. Nesse sentido, optou-se por selecionar dois grupos em cada uma das quatro chamadas públicas realizadas até o momento da pesquisa: um representando as organizações que apresentam maior evolução em relação às suas condições iniciais após as intervenções desencadeadas pelo PMG e outro representando as de menor evolução. 
Maior e menor evolução a partir da atuação das entidades de ATER aqui é utilizada como sinônimo de casos de sucesso e insucesso no PMG. Com esta apreensão de sentido, expressa-se aqueles casos que apresentaram melhores resultados comparativos em relação à situação em que se encontravam antes do início das atividades do PMG. É sabido, porém, que as mudanças ocorridas no período de intervenção das entidades de ATER não são exclusivamente decorrentes desse programa. Por isso, buscou-se também compreender em campo os outros elementos que condicionaram as organizações. Com essa opção, portanto, não se assume que os casos sejam representativos de toda a população, mas que suas realidades de sucesso e insucesso podem contemplar elementos comuns aos demais casos.

Para tanto, foram definidas quatro variáveis, que seguiram como critérios para a escolha dos casos.

I. Ampliação das parcerias;

II. Aumento do faturamento;

III. Ampliação do acesso a mercados institucionais de alimentos;

IV. Aumento do número de associados e de sua participação nas cooperativas.

Após isso, os responsáveis pela entidade de ATER elencaram cinco cooperativas que consideravam sendo de sucesso e cinco de insucesso. A partir dessa indicação preliminar pela entidade de ATER, confrontou-se as cooperativas escolhidas com os resultados do critério de escolha supracitado, verificando aquelas de sucesso que apresentavam melhores índices e as de insucesso que apresentavam piores índices, e dessa listagem, as cooperativas que seriam estudadas foram definidas aleatoriamente pelos pesquisadores. 
Os dados foram coletados através de entrevistas com os atores envolvidos na implementação do Programa Mais Gestão - PMG. Assim, foram realizadas 18 entrevistas com os dirigentes das cooperativas, atores locais que relaciona com a cooperativa, a entidade executora do serviço de ATER e representantes do MDA. As entrevistas foram gravadas e posteriormente trasncritas para tratamento dos dados.

O tratamento dos dados foi realizado por meio da análise de conteúdo. Bardin (2011), caracteriza a análise de conteúdo como um conjunto de técnicas para apreciação de processos comunicativos cujo resultado é a descrição do cientifica do assunto abordado nos discursos. Nas palavras de Laville e Dionne (1999) a análise de conteúdo visa realizar a extração das recorrências na comunicação e revelar um significado geral.

Buscando sintetizar as informações originadas, e para promover uma análise mais objetiva, os principais tópicos das entrevistas foram destacados e relacionados a três dimensões propostas: implementação, organizativa e territorial. A partir daí, foram sistematizadas as avaliações por meio de análise de conteúdo, na perspectiva dos atores envolvidos na implementação do PMG. Posteriormente foram feitas reflexões e sugestões que contribuem para a implementação do programa, destacando pontos fortes, elucidando desafios e apontam para alguns aprimoramentos.

a) Dimensão de Implementação: refere-se à apropriação dos objetivos e da metodologia, a partir da entidade executora e suas relações com MDA e os beneficiários. Enfatizando: a equipe técnica; a seleção das cooperativas; a gestão do Programa e a metodologia;

b) Dimensão Organizativa: referem-se à realidade organizacional no que diz respeito à gestão, comercialização, recursos humanos, financeiro. A atuação da entidade de ATER (metodologia, equipe), os resultados, ou seja, a percepção dos 
dirigentes sobre que ações realizadas pela equipe do PMG, a relação com a entidade de ATER e os resultados gerados sobre as ações do Mais Gestão no desenvolvimento da cooperativa;

c) Dimensão Territorial: refere-se à interferência do contexto e dos atores locais e territoriais no Programa Mais Gestão. As alianças políticas e sociais, rede de relacionamento, espaços de participação e a integração das políticas públicas.

A organização e análise dos dados foram realizadas através da análise de conteúdo. A análise de conteúdo é uma técnica de análise rigorosa que descreve cientificamente os assuntos abordados nos discursos, sendo marcada pela diversidade de adaptação que pode ser feita em campo. Quando se analisa uma temática através da análise de conteúdo podem-se coletar as informações, transcrever e dividir o texto em alguns temas principais e, eventualmente em subtemas (BARDIN, 2011).

Durante a pesquisa de campo, os áudios das entrevistas foram gravados, transcritos na integridade (incluindo hesitações, risos, silêncios, espantos e estímulos do pesquisador), com o auxílio do programa Express Scribe 5.81, garantindo a captação de questões referentes à subjetividade do entrevistado. Esses entrevistados foram codificados, atribuindo a eles codinomes categorizados como: a) representante da entidade executora; b) representante da cooperativa; c) representante da entidade parceira.

Posteriormente, para dar significados aos discursos de modo geral, foram subdivididos os conteúdos dos relatos e enquadrados com base nos discursos dos entrevistados. Essa sequência lógica corrobora com as recomendações de Bardin (2011), que sugere três etapas para condução da análise de conteúdo:

1- Primeira leitura e organização do material que será analisado. 
2- Releitura com atenção para o enquadramento do conteúdo em categorias que darão os significados aos discursos.

3- Seleção das categoriais analíticas, ajuste dos discursos em busca de um significação geral para os dados.

Dessa maneira foram reconstituídos os discursos, gerando resultados a partir da perspectiva dos atores envolvidos na implementação do Programa Mais Gestão.

\section{PERCEPÇÃO DOS ATORES ENVOLVIDOS NA IMPLEMENTAÇÃO DO PROGRAMA MAIS GESTÃO}

\subsection{Dimensão de implementação}

Primeiro ponto de saliência é a escolha das cooperativas beneficiadas pelo Programa Mais Gestão - PMG. As chamadas indicavam, em geral, que tal escolha seria compartilhada igualitariamente entre a entidade contratada e o MDA, especificamente a delegacia federal de cada estado. Entretanto, percebe-se que em cada estado esta etapa se deu de uma forma, e cada uma implicou de uma maneira no desenvolvimento das ações e resultados do programa. Em outros termos, não houve padronização do perfil das cooperativas participantes e os critérios superficiais sugeridos nas chamadas não permitiram objetividade e rigor no processo de seleção das organizações.

Relata o representante da entidade executora "quem estava à frente disso era a delegacia do MDA do estado e o perfil dos gestores, da delegacia, era um perfil absolutamente político e nada técnico", sustentando a permanência de cooperativas por critérios também políticos, o que à frente poderia representar um gargalo para o desenvolvimento dos trabalhos, uma vez que a organização poderia não ter potencial para acesso a mercados institucionais. 
Outra questão relevante é a composição da equipe técnica, a qual é determinada pela chamada pública como integrada por sete técnicos em caráter multidisciplinar. Foi consenso entre as entidades executoras que o número sugerido pelo MDA é bem inferior ao que realmente é demandado, diante do volume e a complexidade de ações necessárias para as cooperativas. Todas as entidades tiveram que acessar consultores externos, mais que aqueles diretamente envolvidos na execução, em função das especificidades das demandas das beneficiárias. Abaixo, segue a fala de um entrevistado técnico de ATER sugestivo sobre essa questão:

Eu acho que não faz muito sentido ter uma equipe rígida, obrigatória, tão fixa, porque o pessoal que eu preciso hoje é diferente do pessoal que eu precisava nas fases anteriores lá do pré-diagnostico, diagnostico (Entrevista 1).

Não obstante essas questões, é mister apresentar a percepção sobre os instrumentos metodológicos do PMG, os quais dizem respeito à natureza do processo de implementação, os meios pelos quais o programa acontece. De maneira geral, as perspectivas das executoras convergem na afirmação de que os instrumentos de diagnóstico são por demais abrangentes e deslocados da realidade das cooperativas da agricultura familiar, ao menos da maioria delas, enfocando o perfil daquelas mais consolidas e estruturadas. Um representante de uma executora afirma que "a gente sofreu um pouco no diagnóstico, em alguns momentos para enquadrar as cooperativas pequenas nos formulários, né".

A fase de diagnóstico, de maneira geral, foi muito extensa, causando uma série de complicações para a execução das chamadas, principalmente à etapa mais esperada pelas cooperativas, que são as visitas técnicas.

O diagnóstico tinha bastante falha, ao mesmo tempo que ele era bastante abrangente, com um conjunto enorme de perguntas e era um cansativo para a 
cooperativa a aplicação, várias questões não eram bem abrangidas, as respostas, como você ia marcando, não cabia exatamente a resposta, por exemplo, tinha uma questão focada em exportação, que perguntava se a cooperativa tinha interesse. Se você marcasse não tinha interesse, você caia num espaço não se aplica para um monte de questões que elas eram aplicáveis para a cooperativa. Então o instrumento fazia generalizações ruins, eu lembro um pouco disso, que não ajudou muito (Entrevista 2).

Também pode-se fazer reflexões sobre o instrumento plano de aprimoramento, produto fundamental no âmbito do PMG, pois trata-se do planejamento detalhado da intervenção direta da equipe técnica, orientando as visitas técnicas, outra etapa do programa. O MDA já fornece previamente um modelo, uma orientação do que deve conter nos planos e de como ele deve ser elaborado, subsequente à matriz estratégica, supostamente com envolvimento dos dirigentes da cooperativa e posterior devolução para ratificações.

Porém, como relatado durante a pesquisa, o Plano é um documento muito grande e complexo, de tal forma que alguns técnicos questionaram a necessidade e funcionalidade de algo com essa densidade. A preocupação é que a quantidade de informações sistematizadas, cujos principais interessados e usuários deveriam ser as cooperativas, pode ser mais uma pilha de papel arquivada, da qual se aproveitam algumas poucas partes, principalmente o cronograma de ação, que é o mais útil. Um técnico de ATER ressalta:

[...] acho que ele é um documento [plano de aprimoramento] grande demais, denso demais. Não vejo necessidade, né? Eu me pergunto; quem é que vai ler aquele plano, né? Além da própria equipe que o escreveu. No máximo o pessoal vai pegar lá no final aquelas tabelas de resumo, né? (Entrevista 3). 
Diante desse contexto e das problemáticas captadas na percepção dos representantes de ATER, algumas sugestões podem ser elencadas para aprimoramento: (i) As entidades de ATER poderiam acompanhar de maneira mais efetiva o comportamento organizacional das cooperativas e suas mudanças diante do acesso ao mercado institucional - essa afirmativa se embasa na perspectiva dos agentes de ATER através dos seus relatos.; (ii) uma dilação do tempo do contrato possibilitaria a formação efetiva de lideranças em gestão, ou seja, a apropriação do instrumental e do cotidiano administrativo por alguns cooperados, os quais seriam responsáveis posteriormente para garantir a profissionalização da gestão e a continuidade desse processo estratégico; (iii) ampliar os espaços de interação entre as entidades de ATER contratadas em todo o Brasil. Percebe-se que nas chamadas em execução, esta interação não tem acontecido, a não ser por um único evento, mas que pela sua dinâmica intensa, não possibilitou troca de experiências; (iv) promoção de intercâmbio entre as executoras poderia entrar como uma meta dentro das chamadas, com recursos específicos para isso. Isso possibilitaria com que as experiências fossem compartilhadas e que desafios e problemas na execução fossem superados mais rapidamente, dando qualidade às ações e efetividade aos instrumentos metodológicos.

Para contribuir com essa última sugestão, trata-se de ampliar e tornar efetivo o engajamento das delegacias estaduais do MDA no PMG. Como foi apresentado, este envolvimento é tangente e pode até se tornar prejudicial quando toma apenas caráter político, e pouco institucional. 
4.2 Dimensão organizativa

Inicialmente, a relação maior da entidade de ATER foi com os dirigentes das cooperativas. Os técnicos não conheciam a cooperativa e nem os dirigentes conheciam a entidade de ATER antes do PMG. Isso determinou a necessidade de um breve período de adaptação e reconhecimento da área de trabalho pelos técnicos de ATER e de adaptação ao método por parte dos dirigentes.

Em geral, os entrevistados apontaram em suas entrevistas que a relação entre a entidade de ATER e a cooperativa é amistosa. Algumas das dificuldades apresentadas estão na relação entre as partes, no sentido da conciliação conjunta da agenda e a distância que a entidade fica do lugar, visto que os técnicos ficam na capital.

\subsubsection{Percepção dos beneficiários sobre a implementação do PMG}

Assim como apontado anteriormente na fala dos técnicos das entidades de ATER, esta questão é novamente questionada pelos beneficiários sobre a realização dos instrumentos (diagnóstico e plano de aprimoramento), tem-se o diagnóstico que dura bastante tempo. "Foram uns dois para três meses só nesse processo de levantamento de informações, de dados. Ele terminou o diagnóstico perto de terminar o ano e depois ficou com a pendência de fechar a planilha de 2014" (Entrevista 4). O processo de elaboração do plano de aprimoramento foi feito através de muita discussão interna. A construção foi conjunta com os dirigentes das cooperativas e tudo que está no plano diz-se condizente com a realidade de cada cooperativa.

Fizemos o diagnóstico, aí fizemos o planejamento das atividades, apresentado. Entregaram o trem impresso para a gente, e quando voltou, aqueles prazos que a gente tinha definido, nós já 
tínhamos feito as coisas que era para o mais gestão concordar, entendeu? Então assim, ficou a desejar, né? Poderia, talvez, a gente fez com o conhecimento da gente, a trancos e barrancos, nós poderíamos ter feito melhor. Talvez, né? Com mais conhecimento, com calma e tal. Então eu vejo assim, a gente fica muito na conversa e tem horas que as ações são bem demoradas (Entrevista 4).

No caso específico do Espirito Santo, onde as cooperativas que ainda não fizeram o plano de aprimoramento, o dirigente diz que "da maneira que a entidade de ATER está colocando, eles estão conseguindo resolver [...]". A problemática acentua-se nestes casos, onde a entidade de ATER não conseguiu executar a meta, mas aparentemente o dirigente têm restrições a apontar os entraves. Para este mesmo caso, o dirigente sequer conhece a os instrumentos do PMG. No caso onde a cooperativa está aplicando o plano, a observação principal é o mercado institucional e a necessidade de abrir relações com o mercado privado.

No que tange as visitas técnicas realizadas, os dirigentes têm satisfação no conteúdo, capacidade em atender as demandas dos cooperados, porém dizem insatisfeito com baixo número de visitas realizadas. "As visitas têm um espaço muito grande, são realizadas de 2 em 2 meses, tem que ser a cada 15 dias ou uma vez por mês, está aqui mais próximo".

O PMG ajudou no planejamento, conseguimos código de barras que não foi fácil, dialogou intensamente com as empresas, encaminhou a documentação, desenhou e construiu nossa marca. Um trabalho bacana que fizeram com a gente e temos medo disso acabar, entendemos que cresceu tanto que queremos que dê continuidade (Entrevista 5). 
4.2.2 Resultados do PMG na visão dos beneficiários

Os maiores relatos de resultado do PMG com as cooperativas são sob questões que envolvem a organização financeira e de documentos. “Um trabalho igual do Mais Gestão começa a abrir os horizontes dos cooperados. É um crescimento. O desafio todo ano vai ser maior com o crescimento da cooperativa. Tem que saber mexer no dinheiro, aplicar. Então, se não tiver esse cuidado vai botar a perder".

Do ponto de vista da comercialização é unanimidade que houve melhorias nos últimos anos. Difícil foi a identificação deste resultado enquanto resultado da implementação do PMG.

Após esse período do PMG, a cooperativa melhorou o volume de produção, e em menor proporção, teve melhoria na diversidade de produtos comercializados para o PNAE e isso gerou um resultado capaz de melhorar a relação entre os cooperados e vender parte da produção no mercado privado através do mercadinho que foi aberto pela cooperativa e já tem uma marca de feijão, com código de barra registrado. Trabalhamos por ano, uns 200 a 400 mil reais. Não vendemos nem para feira e nem para o mercado local. Apenas para o PNAE. Antes, trabalhávamos 30 produtos hoje estamos com 42 produtos (Entrevista 6).

Para esta cooperativa, a maioria dos resultados no período vem do protagonismo da própria cooperativa e o PMG como um apoio institucional do que técnico, de instrumentalização profissionalização da gestão. 


\subsection{Dimensão territorial}

Essa dimensão visa compreender como os aspectos territoriais interferem, potencializam ou debilitam os efeitos do PMG. Nesse sentido, busca mapear as relações do contexto local das organizações, a interação entre os diversos atores presentes no território, o histórico de atuação, as alianças políticas e sociais, a rede de relacionamentos, os espaços de participação e a integração das políticas públicas.

\subsubsection{Experiências cooperativistas passadas}

Muitos entrevistados já tiveram em períodos anteriores alguma experiência com cooperativismo. No caso do Espirito Santo, destaca-se o papel dos imigrantes que vieram da Europa em grande número e já traziam vivências relacionadas à organização cooperativa. Por outro lado, foi muito mencionada a falta de uma cultura associativista, o que traz desafios para a participação e engajamento efetivo da comunidade.

Em Minas Gerais, os entrevistados relataram que há menos de trinta anos atrás, uma série de experiências cooperativas fracassou e consequentemente deixou no imaginário dos agricultores uma percepção negativa, causando entraves devido à falta de confiança no processo de criação de novos empreendimentos cooperados.

Então muita gente aqui na região perdeu muito café lá na cooperativa que quebrou, perderam bastante café. Então aqui, ali... aí... quando se falava em cooperativa, o pessoal ligava a ela. Então tem um paradigma dos produtores aqui, com o cooperativismo. Porque falava em cooperativa e eles não pensavam em outra coisa, ligavam diretamente com ao fracasso (Entrevista 7). 
No caso de São Paulo, um dos dirigentes destacou que, ao contrário desse período anterior, o momento do cooperativismo atual é novo, pois está mais solidamente ancorado nos princípios da Economia Solidária.

\subsubsection{Motivo de constituição}

Neste contexto territorial, pode-se dizer que o grande estímulo à constituição de cooperativas está atrelado às políticas públicas. "O governo, quase que obrigou, através da lei, a criação de cooperativas". A constituição das cooperativas se deu sobretudo para atender ao PAA e ao PNAE, com intuito de aprimorar o processo de comercialização dos agricultores.

Compreende-se com a imersão empírica nessa pesquisa, que há cooperativas mais com as relações sociais mais fortalecidas e outras com menor participação dos cooperados. Observa-se que, as organizações constituídas apenas para acessar políticas públicas encontram maiores desafios com o trabalho coletivo nas cooperativas, pois estão erguidas sobre frágeis bases sociais, funcionando com uma cooperação induzida através da exigências das políticas públicas. Ao contrário, as cooperativas constituídas no âmbito dos movimentos político-organizativos como os Sindicatos de Trabalhadores Rurais - STRs e o Movimento dos Trabalhadores Rurais Sem Terra - MST, possuem base social mais forte, engajamento dos seus membros e maior entendimento do cooperativismo. Ou seja, aquelas criadas por iniciativa dos próprios agricultores, a partir de uma demanda concreta, que emergiu de um processo de amadurecimento da comunidade acerca da percepção sobre suas necessidades e de um conjunto de valores e princípios já compartilhado por aquele grupo.

Em grande medida, associações como a Coopas, como a Coopraf, elas surgem de processos de disputa interna no assentamento, são rachas que acontecem ali e elas se criam pra acessar o PAA, sabe... o 
objetivo não é criar uma cooperativa, o objetivo é acessar o PAA. Mas como é que acessa o PAA? Não, tem que ter a cooperativa, então cria a cooperativa. Então, se reúnem em torno desse objetivo muito pequeno, muito particular, sabe? E aí de fato, o salto desse objetivo muito particular para algo maior ele é difícil, ele é lento. Cê precisa... criar essa liga, que é a liga da Cooperação, né, depois de ter criado a Cooperativa (Entrevista 8).

Portanto, sugere-se que as cooperativas que estão mais aptas a serem atendidas pelo Mais Gestão são aquelas que já estão com um processo de constituição mais amadurecido, pois as que foram criadas no contexto de acessar o PAA e o PNAE, ainda precisam ser fortalecidas em outros aspectos antes de focarem o aprimoramento da gestão e o acesso aos mercados.

4.3.3 Redes de articulação territorial e relação com o poder público

A análise do contexto das articulações territoriais tem relação direta com o acesso à política, além disso, tem interferências que devem permitir refinar as modalidades de implementação da política nos territórios. Na realidade das cooperativas entrevistadas, encontram-se articulações de naturezas heterogêneas. Um ponto comum está na constituição das cooperativas, que foram majoritariamente concebidas pelos sindicatos rurais. Outros atores, em menor intensidade, também contribuíram neste processo (Instituto Capixaba de Pesquisa, Assistência Técnica e Extensão Rural - INCAPER, Prefeitura, União das Cooperativas de Agricultura Familiar e Economia Solidária - UNICAFES, Secretaria da Agricultura, Pecuária, Irrigação, Pesca e Aquicultura - SEAGRI e o sindicato patronal).

Essas articulações locais foram impulsionadas, após a necessidade aparente pela política pública (PNAE), que demandou maior articulação entre os agricultores 
para o acesso a esse mercado. Todas essas relações são fundamentais para as cooperativas, elas são anteriores ao PMG e ajudam desde a sua constituição.

A cooperativa já tinha o apoio do sindicato, do INCAPE, da UNICAFES, do SEBRAE que ajudaram a fazer um plano de negócio. Então quando a ATER mais gestão chegou estávamos no início da atividade de elaboração do plano de negócio. Então o ATER gestão melhorou este que já estava acontecendo (Entrevista 9).

Assim como as redes preexistentes favorecem a implementação do PMG, esse programa tem estimulado a criação de cooperativas em locais onde existe pouca ou nenhuma articulação entre os atores. Isso foi encontrado na fala de entrevistados que diziam ser quase obrigatória a constituição de cooperativas para a região não ficar de fora desse processo. As influências desse fenômeno devem ser destacadas para melhor analise dos desdobramentos causados por essas iniciativas.

A relação é muito boa de trabalho, de parceria. Tanto com a cooperativa de crédito, quanto com a cooperativa de produção. Nós somos parceiros. Tanto é que, pra uma reunião, se o diretor não vai, a gente leva a cooperativa do mesmo jeito. Se eles vão, a gente ta indo junto também, mesmo que não vá o diretor nosso. Então é igual eu falei, quando a gente precisa sentar e discutir alguma coisa que a gente não concorda, a gente resolve aqui. Mas quando a gente vai pro campo não, a gente vai junto. Não vai só o sindicato, vai o sindicato e as duas cooperativas (Entrevista 10).

Há cooperativas, como no caso de São Paulo, que estão articuladas a várias outras cooperativas e grupos da região. Buscam articulações com a Prefeitura, organizam grupos de consumo, trabalham em aliança com outras cooperativas, demandam cursos junto ao Serviço Brasileiro de Apoio às Micro e Pequenas 
Empresas - SEBRAE, Universidade Federal de São Carlos - UFSCAR, participam do Conselho Municipal de Desenvolvimento Territorial. Esse movimento políticoorganizativo cria uma identidade favorável à ação conjunta entre os grupos que constituem essa rede, contribuindo na interação entre esses atores, melhorando o desenvolvimento da cooperativa.

O histórico de relação com o poder público municipal é posto como bom, porém contribui pouco com o desenvolvimento das cooperativas. Em síntese, o que foi dito é que as prefeituras ajudam somente naquilo que são obrigadas a fazer.

É uma ajuda de discurso, sem nenhuma ajuda financeira e pouco ou nada de equipamentos. O apoio do poder público municipal é em relação de conversa, diretamente ligada a prefeitura por causa o PNAE e agora para passar os contatos das entidades filantrópicas que queremos fornecer alimentos do PAA. Mas do ponto de vista do PMG, a prefeitura (...) é capaz de nem saber que estamos inseridos nesse programa (Entrevista 11).

Em outros casos, onde a relação de dependência com o mercado institucional é grande, o poder público tem sido fundamental e consequentemente tem gerado certa dependência por parte das cooperativas. Porém, a situação não é estanque, as cooperativas têm tentado buscar soluções para atingir outros mercados, trabalhando cadeias mais curtas de produção/consumo.

Em nenhuma das entrevistadas, o poder público municipal tinha plena noção do PMG, algumas não sabiam sequer do que se tratava e outras ouviram falar superficialmente. Observou-se que o PMG não estimulou a relação entre o poder público e as cooperativas, nem aprimorando essas relações onde já existiam, nem incentivando novas articulações. Os técnicos da entidade de ATER não priorizaram 
essa questão, focando sua agenda de trabalho na execução do pré-diagnóstico, diagnóstico e plano de aprimoramento.

\section{CONCLUSÃO}

A pesquisa demonstra claramente a importância da realização de uma avaliação da política pública sob a ótica dos atores envolvidos no processo de implementação do PMG, contribuindo assim para monitoramento e avaliação dessa política, uma vez que, com esta abordagem diminui as chances dos erros oriundos das políticas públicas tipo top down como é o caso do PMG.

No entanto, os instrumentos do programa em certos momentos foram limitantes à ação das entidades de ATER e à capacitação das cooperativas. O longo tempo para fazer o diagnóstico desgastou os dirigentes das cooperativas e reduziu a credibilidade do programa. Isso ainda contribuiu para criar a percepção de falta de resultados factíveis do PMG, já que as intervenções técnicas ficaram para os últimos meses de execução. Pode-se considerar, pelos relatos em campo, que o PMG contribuiu para criar reflexões basilares aos negócios cooperativas e no desenvolvimento de processos importantes para a comercialização de produtos alimentícios por meio de ações pontuais. Porém, o programa não tem conseguido instrumentalizar, e assim, profissionalizar a gestão das cooperativas atendidas.

Do ponto de vista organizativo, de resultados para as cooperativas e de contribuição para aprimoramento do PMG, emerge da realidade empírica elementos importantes para a compreensão de novas rotas que podem ser seguidas pelo programa. Ou seja, a proposta metodológica do PMG ainda que seja genérica, não é suficiente ao ponto de adaptar-se para qualquer cooperativa da agricultura familiar. Da maneira como está posto, as cooperativas menos estruturadas e mais recentes, com menor engajamento político e sem definição de um negócio, podem não ter um resultado tão satisfatório quanto aquelas que já possuem uma inserção comercial 
consolidada e experiências de acesso ao mercado institucional. Em última análise, o PMG poderia aprimorar a sua chamada pública, apontando diferentes métodos de intervenção de acordo o grau de complexidade em que se encontra a cooperativa beneficiária.

Contudo, identificou-se, a partir da análise das entrevistas que, do ponto de vista territorial a gênese da cooperativa e a rede de atores locais com os quais ela se relaciona são categorias analíticas primordiais para compreensão do desenvolvimento organizacional. Sugerindo assim, novas pesquisas focadas nas redes que se estabelecem para implementação do programa. Tais elementos do contexto territorial traduzem o dinamismo do cooperativismo em determinados municípios e podem explicar a proatividade de certas organizações em resposta aos estímulos do PMG.

\section{REFERÊNCIAS}

BARDIN, L. Análise de conteúdo. São Paulo: Edições 70, 2011.

BRASIL. Censo Agropecuário 2006: Resultados preliminares. Disponível em: ftp://ftp.ibge.gov.br/Censos/Censo_Agropecuario_2006/. Acesso em: 17 nov. 2015.

BRASIL Ministério do Desenvolvimento Agrário. Fundamentos teóricos, orientações e procedimentos metodológicos para a construção de uma pedagogia de ATER. Brasília: MDA/SAF, 2010.

CHIAVENATO, I. Administração nos novos tempos. 2.ed. Rio de Janeiro: Elsevier, 2010.

CHIAVENATO, I. Administração: teoria, processos e prática. 4.ed. Rio de Janeiro: Elsevier, 2007.

COCHRAN, W. G. Técnicas de Amostragem. John Wiley \& Sons, Inc., New York. Rio de Janeiro: USAID, 1965. 
COHEN, E.; FRANCO, R. Avaliação de projetos sociais. Petrópolis: Vozes, 2008.

COSTA, F. L.; CASTANHAR, J.C. Avaliação de programas públicas: desafios conceituais e metodológicos. Rio de Janeiro: Revista de Administração Pública, v. 37, n.5, 2003.

GRISA, C.; SCHNEIDER, S. Três gerações de políticas públicas para a agricultura familiar e formas de interação entre sociedade e estado no Brasil. Revista de Economia e Sociologia Rural, v. 52, p. 125-146, 2014.

HOFLING, E. M. Estado e Políticas (Públicas) Sociais. Caderno Cedes, nº 55, p. 30 - 41, 2001.

LAVILLE, C.; DIONNE, J. A construção do saber: manual de metodologia da pesquisa em ciências humanas. Belo Horizonte: UFMG, 1999.

MATIAS-PEREIRA, J. Reforma do Estado e controle da corrupção no Brasil. Cadernos de Pesquisa em Administração, v. 12, n. 2, p. 1-17, 2005. MENEZES, L. C. M, de. Gestão de projetos. 2.ed. São Paulo: Atlas, 2003. MIMICOPOULOS, M; KYJ, L; SORMANI, N. Indicadores de governança pública: uma revisão de literatura. Nova lorque: Nações Unidas, Departamento de Assuntos Econômicos e Sociais, 2007.

MULLER, P; SUREL, Y. A análise de políticas públicas. 2. ed. Pelotas: Educat, 2004.

ORTEGON, E.; PACHECO, J. F; PRIETO, A. Metodología del marco lógico iónpara planificación, El surgimento y la evaluación de proyectos y programas. Santiago: CEPAL, 2005; 124p. Disponível em: $\quad$ http://www.cepal.org/es/publicaciones/5607metodologia-del-marco-logico-para-laplanificacion-el-seguimiento-y-la-evaluacion. Acesso no dia 17 de nov. de 2015.

OSTROM, E. Institutional Rational Choice: An Assessment of the Institutional Analysis and Development Framework. In: Sabatier, P. Theories of policy process. Westview Press, 2007. 
RIOS, G. S. L. O que é cooperativismo. São Paulo: Brasiliense, 2007.

RODRIGUES, C. M. Conceito de seletividade de políticas públicas e suas aplicações no contexto da política de extensão rural no Brasil. Cadernos de Ciência \& Tecnologia, Brasília-DF, v.14, $\mathrm{n}^{\circ} .1, \mathrm{p} .113-154,1997$.

RUA, M. G. Análise de políticas públicas: conceitos básicos. Brasília: ENAP, 1997.

SILVA, C. M. da. Agricultura e Cooperação Internacional: a atuação da American International Association for Economic and Social Development (AIA) e os programas de modernização no Brasil (1946-1961). 2009, 225 p. Tese (doutorado em história das ciências e da saúde) - Casa de Oswaldo Cruz/Fiocruz, Rio de Janeiro.

WILDAVSKY, A. The Policy of Budgetary Process. 2. ed. Boston: Little and Brown, 1992.

WORLD BANK. Designing Project Monitoring an Evaluation. Washington: World Bank, Operations Evaluation Department, 1996. 
